\title{
Association between anomalies of moisture flux and extreme runoff events in the south-eastern Alps
}

\author{
M. Müller ${ }^{1}$ and M. Kaspar ${ }^{2}$ \\ ${ }^{1}$ Institute of Atmospheric Physics AS CR, Prague, Czech Republic \\ ${ }^{2}$ Charles University, Faculty of Science, Prague, Czech Republic
}

Received: 16 July 2010 - Revised: 24 January 2011 - Accepted: 23 February 2011 - Published: 23 March 2011

\begin{abstract}
The aims of the paper are (i) to describe the annual distribution of extreme runoff events on the Mura, Drava and Sava Rivers, (ii) to demonstrate their association with moisture fluxes, and (iii) to explain their annual distribution by moisture flux climatology. Extreme runoff events were defined as rapid increases in daily mean discharge. Moisture flux anomalies were studied within six pixels of the ERA-40 database around the studied region.

In general, extreme runoff events were concentrated in the summer and autumn and were usually associated with anomalies in moisture flux, mainly from the south. Nevertheless, while southern and western moisture fluxes were typical of Sava River events that occurred mainly in autumn, summer events prevailed on the Mura River and were frequently associated with moisture fluxes from the east or the north.

It is remarkable that moisture fluxes from the west and south have their maxima in the autumn, whereas those from the east and north have their maxima in the summer. Therefore, the climatology of moisture flux seems to be one of the major reasons for the annual distribution of extreme runoff events in the study region. This result should be confirmed in other regions in the future.
\end{abstract}

\section{Introduction}

The Alps are one of the most significant climate boundaries in Europe (Wanner et al., 1997). Considering the heavy precipitation and floods in the Mediterranean region, they are often associated with convective storms in the warm sectors of cyclones (Homar et al., 2007). In comparison, major central-European floods are characterised by non-convective,

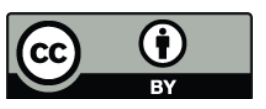

Correspondence to: M. Müller

(muller@ufa.cas.cz) regional rains that occur in the cold, rearward sector of a cyclone. Cyclones are frequently of Mediterranean origin and affect central Europe as they move to the north-east along the so-called "Vb track" (Seibert et al., 2007; Petrow et al., 2007). This generalized cyclone track runs along the Alps into eastern Europe. Therefore, the south-eastern part of the Alps is a very interesting area where both types of heavy precipitation events share their impacts through extreme runoff events.

There are many studies regarding the moisture sources for precipitation in various regions or river basins (e.g., Stohl and James, 2005). With regard to the Alps, Sodemann and Zubler (2010) recognised the north Atlantic as a major source of precipitation in the northern part of the mountains and the Mediterranean as an important source of precipitation in the Southern Alps. Nevertheless, the proportion of different moisture sources varies significantly in the Southern Alps throughout the year, while a pronounced moisture source maximum occurs in autumn in the western Mediterranean. The well-pronounced seasonal and the inter-annual variability of the Mediterranean moisture source seems to be a probable reason for the larger variability in precipitation and, consequently, higher frequency of precipitation extremes in the Southern Alps detected by Frei and Schär (1998).

Our previous research projects ( $\breve{e z a ́ c ̌ o v a ́ ~ e t ~ a l ., ~ 2005 ; ~}$ Müller et al., 2009b) as well as other studies (Keil et al., 1999; James et al., 2004) have clearly demonstrated the association of heavy precipitation and floods with intense fluxes of moisture in the troposphere. A similar finding was confirmed for the Southern Alps too by numerous case studies (Massacand et al., 1998; Reale et al., 2001; Turato et al., 2004). This finding inspired our study for a "quantitative classification of the circulation types" (Müller and Kašpar, 2010). When applied to extreme rainfall-runoff events in various central European river basins, it enables the distinguishing of several homogenous regions with different synoptic causes of rapid increases in runoff. The

Published by Copernicus Publications on behalf of the European Geosciences Union. 


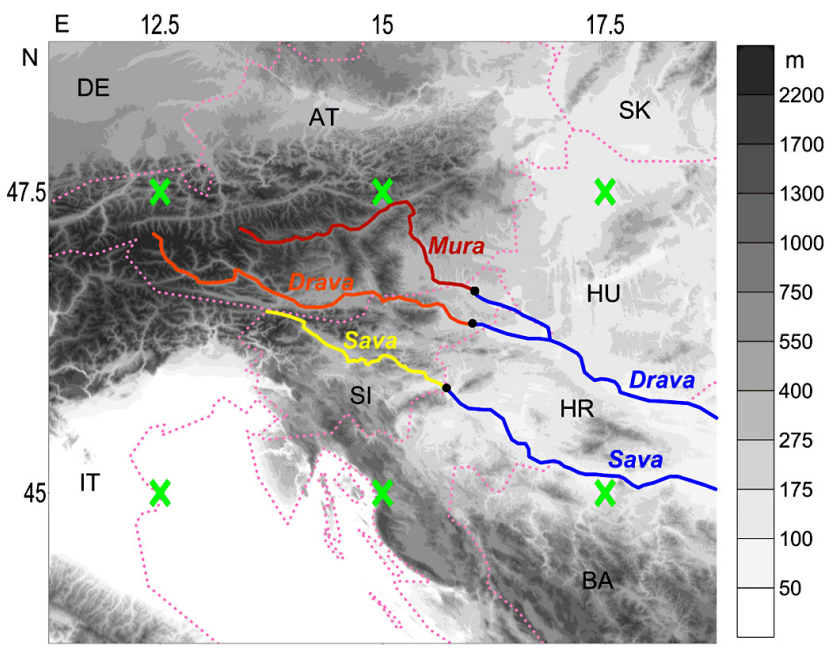

Fig. 1. The topography of the studied area. The studied parts of the rivers are distinguished by different colours; black dots represent the water gauges (see Table 1). Green crosses mark the centres of the studied pixels of the ERA-40 grids.

south-eastern Alps were recognised as one of the regions where these events were concentrated in the autumn (Müller et al., 2009a), and were frequently associated with significant moisture flux anomalies from the south or east (Müller and Kašpar, 2010). The aims of the present paper are: (i) to describe the annual distribution of extreme runoff events in the south-eastern Alps (Sect. 3), (ii) to demonstrate their association with moisture fluxes (Sect. 4.2), and (iii) to explain the annual distribution by the moisture flux climatology (Sect. 4.3).

\section{Data and methods}

The methodology consists of two main steps, which are described below. Primarily, extreme runoff events were selected (Sect. 2.1) from 1958 to 2001 covered completely by the database ERA-40, which was used for the evaluation of moisture flux anomalies (Sect. 2.2).

\subsection{Selection of reference events}

The hydrological data needed for selecting extreme runoff events were provided by the Global Runoff Data Centre (GRDC). The GRDC database is comprised of values of mean daily flow $\left(Q_{\mathrm{d}}\right)$, among others, for the three rivers running eastward from the south-eastern Alps (Fig. 1). Catchments with similar areas were selected and are listed in Table 1.

Normally, the magnitude of a flood is evaluated by peak flow. However, this value is substantially affected by nonmeteorological factors, mainly by the summation of the runoff from individual tributaries (Brázdil et al., 2005). Therefore, the daily resolution of discharge data is sufficient
Table 1. Studied catchments

\begin{tabular}{llcc}
\hline River & Station & Area $\left[\mathrm{km}^{2}\right]$ & Data range \\
\hline Mur/Mura & Gornja Radgona & 10197 & $1958-2001$ \\
Drau/Drava & Borl & 14662 & $1958-1980,1990-2001$ \\
Sava & Catez & 10186 & $1958-2001$ \\
\hline
\end{tabular}

and better suited to our purposes. Moreover, if we study meteorological causes of floods, it seems to be more appropriate to select reference events that are characterised by a rapid increase in discharge rather than the highest values. A probable reason is that the absolute magnitude of the flood can be significantly influenced by the antecedent saturation. If it is high, a rather non-significant meteorological event can result in high peak flows. Hence, we decided to select extreme runoff events using a more sophisticated criterion:

$Q_{\mathrm{x}}=\frac{\left(Q_{\max }-Q_{\min }\right) Q_{\text {max }}}{Q_{\text {min }}+Q_{\text {med }}}$

where $Q_{\max }$ is the local maximum in the data series of $Q_{\mathrm{d}}$, $Q_{\min }$ is the minimum of $Q_{\mathrm{d}}$ registered 1-4 days before and $Q_{\text {med }}$ is the median of $Q_{\mathrm{d}}$ values calculated from the entire time series. The motive for such a criterion is that the magnitude of runoff-increase (represented by $Q_{\max }-Q_{\min }$ ) is saturation-dependent, with higher values of $Q_{\max }-Q_{\min }$ in cases of more saturated catchments. This factor is balanced by the $Q_{\max } / Q_{\min }$ ratio, which overemphasizes the role of the antecedent saturation. For a detailed discussion of the criterion and its comparison with precipitation totals, please refer to Müller et al. (2009a).

To assess the rarity of an event in a catchment, we defined the variable as follows:

$R=\sqrt{\frac{n}{r}}$

where $n$ is the number of years with data for the respective gauge (see the last column of Table 1) and $r$ represents the ranking of the $Q_{\mathrm{x}}$ value within the study period if only independent maxima are considered. Finally, the significance of an event within the entire study area was estimated by the following equation:

$R_{\mathrm{t}}=R_{\mathrm{S}}+R_{\mathrm{D}}+R_{\mathrm{M}}$

where the letters S, D and M represent the Sava, Drava and Mura rivers, respectively. The root in (2) slightly increases the weight of events that had affected two or all three study catchments since larger events were more significant to our research. The threshold for selecting the reference events was subjectively set at $R_{\mathrm{t}}=1.75$ so that the number of reference events is 39 , i.e., almost one event per year on an average. For example, the October 1998 floods in the Mediterranean (Reale et al., 2001) significantly affected the Drava and Sava rivers and the variable $R_{\mathrm{t}}$ was recorded at a value of 4.72 . 


\subsection{Moisture flux anomalies}

The synoptic data was excerpted from the database of reanalyses ERA-40 (Uppala et al., 2005), with a horizontal resolution of $2.5^{\circ}$. The focus of our study was the four standard isobaric levels $(850,700,500$ and $300 \mathrm{hPa})$ and the six pixels around the study region (Fig. 1). Due to vertical wind shear, we investigated the moisture flux at the individual levels separately and not as a vertically integrated measure. Lower levels were omitted because of the relatively high topography in the study domain.

The grid data of the zonal and the meridional components of moisture flux ( $\Phi_{u}$ and $\Phi_{v}$, respectively) were calculated by the following formulas:

$\Phi_{u}=\rho U Q$

$\Phi_{v}=\rho V Q$

where $\rho$ is the density of air, $Q$ is the specific humidity, and $U$ and $V$ represent the zonal and meridional wind components, respectively. We used a standard coordinate system where the zonal flux from east to west and the meridional flux from north to south are negative. The daily means were calculated for each day from 1958-2001 (16071 calculated means). Because of the coarse resolution of the data, our research was limited to large-scale humidity fluxes.

Apart from the absolute values of moisture flux $\left(\mathrm{gm}^{-2} \mathrm{~s}^{-1}\right)$, normalized values were applied because the absolute values' ranges of $\Phi_{u}$ and $\Phi_{v}$ varied among the six pixels considered, and the abnormality of circumstances seemed to be the main criteria in differentiating the variants of extreme runoff events. The cumulative distribution function was used for these purposes; it assesses the probability of not exceeding the value of $x_{i}$ according to:

$F\left(x_{i}\right)=\frac{i}{L+1}$

Where $i$ is the number of values that were less than or equal to $x_{i}$ and $L$ is the total number of values (in our case, $L=16071$ ). Regarding $\Phi_{u}$, values of $F_{u}$ close to 0 or 1 correspond to an intense flux from the east or the west, respectively. For $\Phi_{v}$, values of $F_{v}$ close to 0 or 1 correspond to an intense flux from the north or the south, respectively. As a result, we were able to compare the extremeness of both horizontal moisture flux components in various pixels and at different vertical levels.

\section{Seasonal distribution of extreme runoff events}

Significant increases in the discharge of the study rivers often coincided (Fig. 2). Among the reference events (with $R_{\mathrm{t}}>1.75$ ), more than half significantly affected two or all three rivers ("significantly" means that the $R_{\mathrm{S}}, R_{\mathrm{D}}$ or $R_{\mathrm{M}}$ values were higher than 1 in the respective catchment). If it

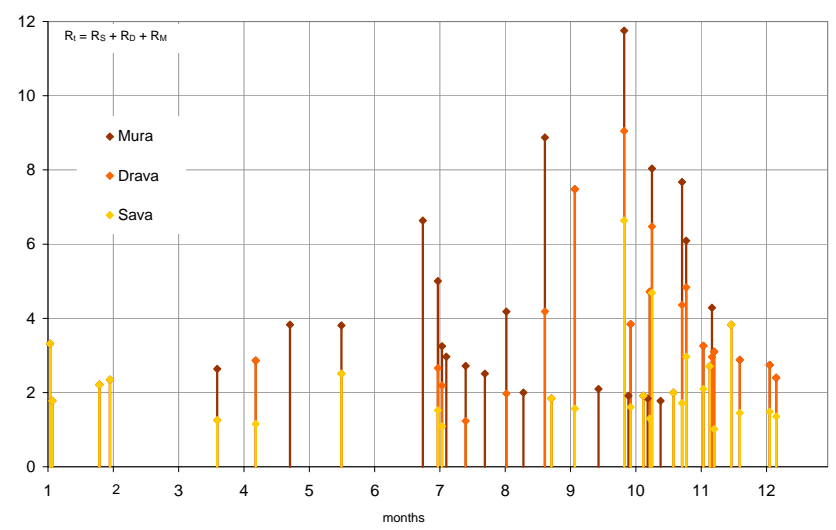

Fig. 2. Annual distribution of extreme runoff events within the study catchments. The height of the whole column represents the magnitude of the event $R_{\mathrm{t}}$ within all three catchments which are distinguished by the colours.

occurred, the affected rivers were probably Sava and Drava (9 cases). In contrast, significant increases of Sava and Mura occurred together only twice without a significant increase of Drava, probably because its catchment location is between the Sava and the Mura (see Fig. 1). Moreover, there was no significant increase in the discharge of the Drava River without a significant increase in the discharge of at least one neighbouring catchment.

From the seasonal point-of-view, the reference events were concentrated in the summer and the autumn months (Fig. 2). More than $75 \%$ of them occurred from mid-June to the end of November. The eight most significant events with $R_{\mathrm{t}}>$ 5 occurred exclusively in this part of the year with no such event occurring in November.

Nevertheless, there were significant differences among the rivers considering the seasonal distribution of discharge increases. The Sava events were distributed most evenly during the year, except during the high summer when the Mura events were most frequent. As mentioned above, the Drava events occurred exclusively together with a significant increase in discharge of one of the neighbouring rivers - of Mura in summer or more frequently, of the Sava in autumn. These results correspond with the findings by Seibert et al. (2007) who detected a very pronounced summer maximum of heavy precipitation frequency in the central part of Austria (where the upper Mura catchment is located), but a main autumn maximum in the south and a secondary autumn maximum in the south-eastern part of the country (where the Drava catchment is located). 


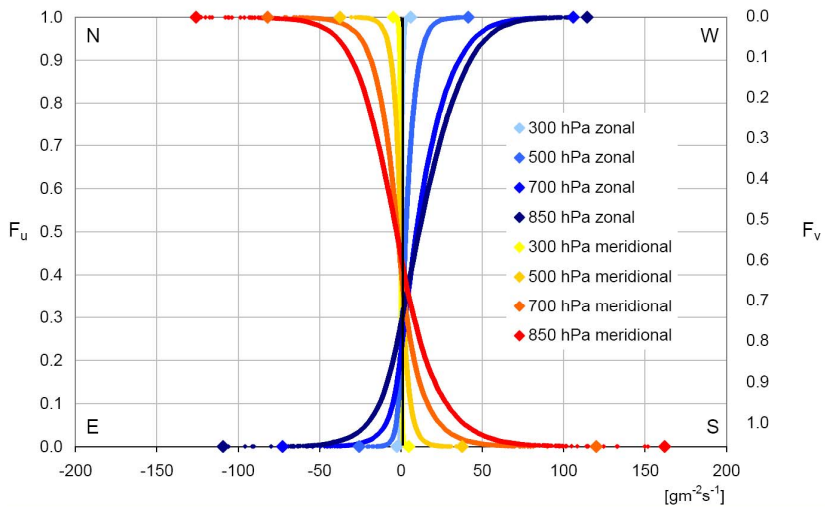

Fig. 3. Daily means of moisture flux components during 1958-2001 at the pixel [15E; $47.5 \mathrm{~N}$ ], and respective values of the cumulative distribution function. Directions of moisture flux components are marked by letters. Extreme values of each component are highlighted by large signs.

\section{Moisture flux associated with extreme runoff events}

\subsection{Magnitudes of moisture fluxes within the study region}

It is obvious from Eqs. (4) and (5) that generally, the magnitude of moisture flux $(\Phi)$ rapidly decreases with altitude due to its dependence on air temperature and density. While the mean value of $\Phi$ in the six study pixels is $27.9 \mathrm{gm}^{-2} \mathrm{~s}^{-1}$ at $850 \mathrm{hPa}$ and 19.6 at $700 \mathrm{hPa}$, it drops to 6.7 at $500 \mathrm{hPa}$ and to approximately 0.76 at $300 \mathrm{hPa}$. The variability in mean values among the individual pixels also decreases from $\pm 20 \%$ at $850 \mathrm{hPa}$ to $\pm 4 \%$ at $300 \mathrm{hPa}$. Nevertheless, day-to-day differences may be even more significant; the statistical distribution of $\Phi$ values was rather asymmetric, with the coefficients of variance increasing from $71 \%$ (at $850 \mathrm{hPa}$ ) to $84 \%$ (at $300 \mathrm{hPa}$ ).

From the viewpoint of this study, the directions of moisture flux are also very important. Figure 3 demonstrates that the western component of the moisture flux was more frequent than the eastern one, mainly at the higher levels and in the northern part of the study region. The northern component was generally slightly more frequent than the southern one.

With regard to the extra strong moisture fluxes, maximal intensities were connected with the southern component at the $850 \mathrm{hPa}$ level and with the western component at all other levels. Relatively slow decrease of moisture flux intensities with altitude was another typical feature of the western component. In contrast, the extra values of the eastern component were least significant and decreased rapidly with altitude.

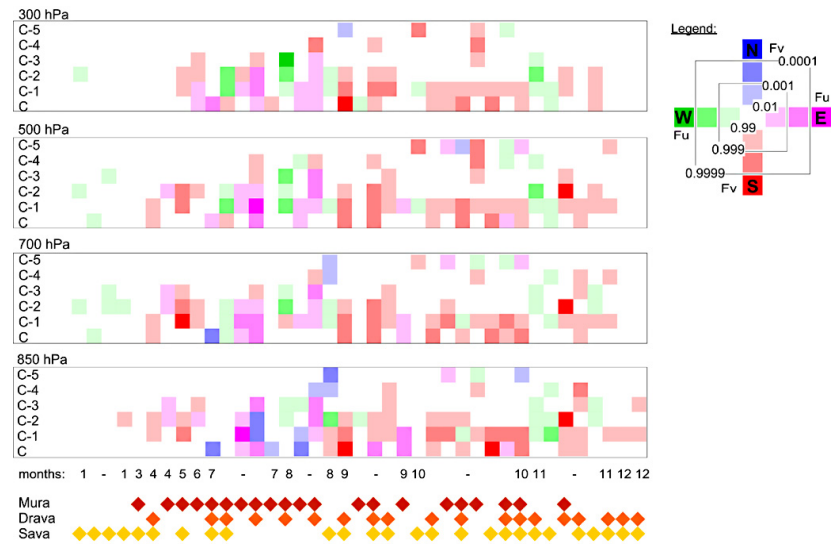

Fig. 4. Extremity of moisture flux during extreme runoff events in the south-eastern Alps. Columns represent 39 individual events arranged according to their annual distribution (respective months are expressed by numbers). Rows in the upper part of the diagram represent the extremity of moisture flux during six days before the river's culmination $(C)$ at the four isobaric levels using the value of the cumulative distribution function $F$. The colour marks the moisture flux component at one of six studied pixels where the moisture flux was the most abnormal during that respective day $(\sim$ the value of $F$ was mostly distant from 0.5 ). Affected catchments are highlighted at the bottom of the diagram.

\subsection{Moisture flux anomalies during extreme runoff events}

The directions and the intensities of moisture flux during extreme runoff events are depicted in Fig. 4. It demonstrates that almost all events were associated with abnormal values of moisture flux, usually during several successive days and at more isobaric levels. Moreover, the absolute maxima (or minima regarding negative $\Phi$ values) of the respective component occurred at least in one pixel during seven reference events. The most frequent direction was from the south, which dominated almost half of all reference events, often accompanied with values of $F_{v}$ being higher than 0.999 . The frequency of the western component was rather similar to the eastern one, but usually without exceptionally high values of $F_{u}$. Finally, the extra intense northern moisture flux occurred rarely and at lower levels.

Another important feature of moisture flux anomalies during extreme runoff events was the difference in their directions during individual seasons. While the southern direction dominated in autumn, the summer months were characterised by the dominance of the eastern direction and also by the exclusive occurrence of the northern anomalies. The abnormal moisture fluxes from the west were distributed rather equally with higher frequencies in November and January.

The seasonal differences correspond with the seasonal distribution of reference events that has already been discussed in Sect. 3. When eastern or northern anomalies occurred, the Mura River was always affected. In contrast, events with 


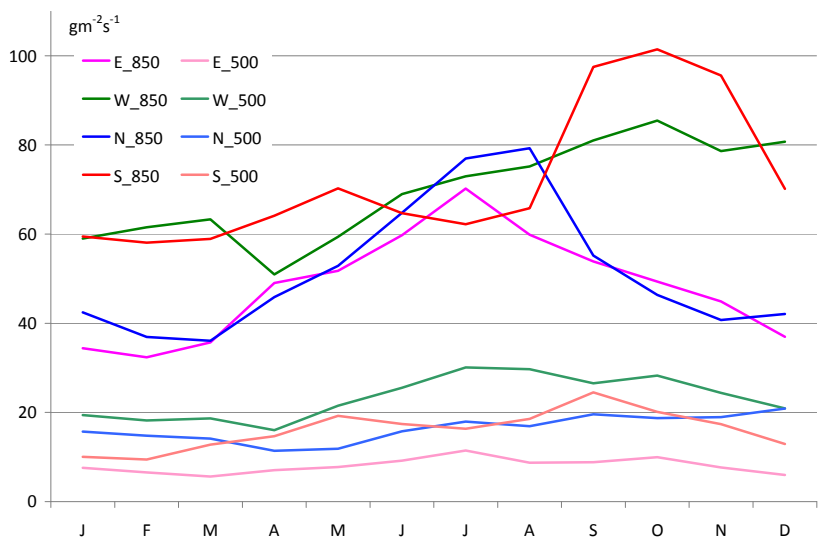

Fig. 5. Annual cycle of intense moisture fluxes within the study region. For each month, the means of 10 most intense moisture fluxes from each direction are depicted. The intensity of moisture flux is averaged over six studied pixels.

western anomalies affected the Sava River. Southern anomalies were most typical of the Drava River events. Therefore, the following section of the paper is related to the climatology of intense moisture fluxes as one of the possible reasons for different seasonal distributions of extreme runoff events among the rivers.

\subsection{Seasonal distribution of intense moisture fluxes}

While considering intense moisture fluxes from the four directions (means of 10 maximum values per month), it has to be noted that there are significantly different annual cycles for each of them, mainly at the lower levels (Fig. 5). At $850 \mathrm{hPa}$, the climatology of intense moisture fluxes noticeably resembles the annual distribution of extreme runoff events in the south-eastern Alps. Significant increases in the discharge of the Mura River were fairly concentrated in summer (Fig. 2) and were often associated with intense moisture fluxes from the east or the north (Fig. 4). It corresponded with the summer maximum of magnitudes of intense moisture fluxes from these directions (Fig. 5). In contrast, significant increases in the discharge of the Drava River were more frequent in autumn (Fig. 2), when they were associated with intense moisture fluxes mainly from the south (Fig. 4). It corresponded with the significant autumn maximum of magnitudes of intense southern moisture fluxes (Fig. 5). Finally, the Sava River discharge increases were distributed equally throughout the year with their main concentration in autumn (Fig. 2). Besides southern moisture fluxes, they were also associated with intense moisture fluxes from the west (Fig. 4); their annual cycle is relatively less significant (Fig. 5).

\section{Conclusions}

While studying the three neighbouring catchments in the south-eastern Alps in detail, we detected several differences in extreme runoff events, defined as rapid increases in the discharge of the rivers. The catchments vary partly in the annual distribution of extreme runoff events. In general, the events were concentrated in summer and autumn. Nevertheless, there was a significant time shift from summer to autumn when moving from the north (Mura River) to the south (Sava River).

Extreme runoff events were usually associated with anomalies in moisture flux which were the most frequent from the south. However, there were differences between the northern and the southern part of the region. While southern and western moisture fluxes are typical of the increases of discharge of the Sava River, summer events in the Mura and Drava catchments were frequently associated with moisture fluxes from the east or the north at the $850 \mathrm{hPa}$ level. This is noteworthy because the eastern moisture fluxes used to be much less significant than the fluxes from the other directions.

The main finding of our study is the fact that the annual distribution of extreme runoff events in the south-eastern Alps fits well with the annual distribution of intense moisture fluxes associated with these events. The eastern and northern moisture fluxes, typical of extreme runoff events in the northern part of the region, are most intense in the summer, when the events are concentrated there. In contrast, the southern and western moisture fluxes which are typical of extreme runoff events in the southern part of the region are most intense in the autumn, when the events are concentrated there. Therefore, the climatology of the moisture flux seems to be one of the reasons for the annual distribution of extreme runoff events in the study region. In future, these results should also be confirmed for other regions.

Acknowledgements. The contribution was prepared under the support of the project no. MSM0021620831 "Geographic Systems and Risk Processes in the Context of Global Change and European Integration" by the Ministry of Education, Youth and Sports of the Czech Republic. The ECMWF is acknowledged for the ERA-40 data, and the Global Runoff Data Centre (GRDC) for the runoff data. Special thanks go to the CIMA research foundation which awarded the Med-storms prize for young researchers to our oral presentation at the 11th Plinius Conference on Mediterranean Storms, Barcelona (Spain), September 2009.

Edited by: G. Boni

Reviewed by: two anonymous referees 


\section{References}

Brázdil, R., Dobrovolný, P., Elleder, L., Kakos, V., Kotyza, O., Květon̆, V., Macková, J., Müller, M., Štekl, J., Tolasz, R., and Valášek, H.: Historical and Recent Floods in the Czech Republic, Masarykova univerzita and Český hydrometeorologický ústav, Brno and Prague, Czech Republic, 370 pp., 2005 (in Czech, including 83 pp. of an English abstract).

Frei, C. and Schär, C.: A precipitation climatology of the Alps from high-resolution rain-gauge observations, Int. J. Climatol., 18, 873-900, 1998.

GRDC: The Global Runoff Data Centre, D-56068 Koblenz, Germany, available at: http://grdc.bafg.de, last access: 14 April 2010.

Homar, V., Jansà, A., Campins, J., Genovs, A., and Ramis, C.: Towards a systematic climatology of sensitivities of Mediterranean high impact weather: a contribution based on intense cyclones, Nat. Hazards Earth Syst. Sci., 7, 445-454, doi:10.5194/nhess-7445-2007, 2007.

James, P., Stohl, A., Spichtinger, N., Eckhardt, S., and Forster, C.: Climatological aspects of the extreme European rainfall of $\mathrm{Au}-$ gust 2002 and a trajectory method for estimating the associated evaporative source regions, Nat. Hazards Earth Syst. Sci., 4, 733746, doi:10.5194/nhess-4-733-2004, 2004.

Keil, C., Volkert, H., and Majewski, D.,: The Oder flood in July 1997: Transport routes of precipitable water diagnosed with an operational forecast model, Geophys. Res. Lett., 26, 235-238, 1999.

Massacand, A. C., Wernli, H., and Davies, H. C.: Heavy precipitation on the Alpine southside: An upper-level precursor, Geophys. Res. Lett., 25, 1435-1438, 1998.

Müller, M. and Kašpar, M.: Quantitative aspect in circulation type classifications - an example based on evaluation of moisture flux anomalies, Phys. Chem. Earth, 35, 484-490, 2010.

Müller, M., Kašpar, M., and Matschullat, J.: Heavy rains and extreme rainfall-runoff events in Central Europe from 1951 to 2002, Nat. Hazards Earth Syst. Sci., 9, 441-450, doi:10.5194/nhess-9-441-2009, 2009.

Müller, M., Kašpar, M., Řezáčová, D., and Sokol, Z.: Extremeness of meteorological variables as an indicator of extreme precipitation events, Atmos. Res., 92, 308-317, 2009b.
Petrow, Th., Merz, B., Lindenschmidt, K.-E., and Thieken, A. H.: Aspects of seasonality and flood generating circulation patterns in a mountainous catchment in south-eastern Germany, Hydrol. Earth Syst. Sci., 11, 1455-1468, doi:10.5194/hess-11-14552007, 2007.

Reale, O., Feudale, L., and Turato, B.: Evaporative moisture sources during a sequence of floods in the Mediterranean region, Geophys. Res. Lett., 28, 2085-2088, 2001.

Řezáčová, D., Kašpar, M., Müller, M., Sokol, Z., Kakos, V., Hanslian, D., and Pešice, P.: A comparison of flood precipitation episode in August 2002 with historic extreme precipitation events on the Czech territory, Atmos. Res., 77, 354-366, 2005.

Seibert, P., Frank, A., and Formayer, H.: Synoptic and regional patterns of heavy precipitation in Austria, Theor. Appl. Climatol., 87, 139-153, 2007.

Sodemann, H. and Zubler, E.: Seasonal and inter-annual variability of the moisture sources for Alpine precipitation during 19952002, Int. J. Climatol., 30, 947-961, 2010.

Stohl, A. and James, P.: A Lagrangian analysis of the atmospheric branch of the global water cycle. Part II: Moisture transports between Earth's ocean basins and river catchments, J. Hydrometeor., 6, 961-984, 2005.

Turato, B., Reale, O., and Siccardi, F.: Water vapour sources of the October 2000 Piedmont flood, J. Hydrometeor., 5, 693-712, 2004.

Uppala, S. M., Kållberg, P. W., Simmons, A. J., Andrae, U., Da Costa Bechtold, V., Fiorino, M., Gibson, J. K., Haseler, J., Hernandez, A., Kelly, G. A., Li, X., Onogi, K., Saarinen, S., Sokka, N., Allan, R. P., Andersson, E., Arpe, K., Balmaseda, M. A., Beljaars, A. C. M., Van De Berg, L., Bidlot, J., Bormann, N., Caires, S., Chevallier, F., Dethof, A., Dragosavac, M., Fisher, M., Fuentes, M., Hagemann, S., Hólm, E, Hoskins, B. J., Isaksen, L., Janssen, P. A. E. M., Jenne, R., McNally, A. P., Mahfouf, J. F., Morcrette, J. J., Rayner, N. A., Saunders, R. W., Simon, P., Sterl, A., Trenberth, K. E., Untch, A., Vasiljevic, D., Viterbo, P., and Woollen, J.: The ERA-40 re-analysis, Quart. J. Roy. Meteor. Soc., 131, 2961-3012, 2005.

Wanner, H., Rickli, R., Salvisberg, E., Schmutz, C., and Schuepp, M.: Global climate change and variability and its influence on Alpine climate - Concepts and observations, Theor. Appl. Climatol., 58, 221-243, 1997. 